\title{
Project-Based Learning: Lessons Learned Teaching Non-Communication Majors
}

\author{
Sarah Symonds LeBlanc, PhD $\odot$
}

Keywords: family communication, project-based learning, instructional communication, communication education, teaching and learning

\begin{abstract}
Family communication, as an upper-level communication course, attracts communication majors and students studying in other disciplines. As such, instructors employ pedagogies that appeal to both majors and non-majors. This essay reflects on how I used project-based learning (PBL) in a family communication course filled with mostly non-majors. The essay highlights my rationale for choosing PBL, provides an explanation of the PBL activity, describes how PBL addresses two key problems I experienced in teaching the family communication course, and offers conclusions regarding lessons learned.
\end{abstract}

Science, Technology, Engineering, and Mathematics (STEM) disciplines rarely provide opportunities for students to interact with students majoring in non-technical fields. This lack of exposure may result in a lack of fundamental communication skills needed to be successful upon graduation (Keshwani \& Adams, 2017). As a result, some non-communication majors elect to take communication courses to acquire these skills. The ratio of majors to non-majors enrolled in any given communication course may vary; however, these demographics still leave many instructors wondering how to approach communication material in a way that it is relevant to non-majors. Thus, this manuscript describes a best practice I employ to meet the needs and desires of both majors and non-majors simultaneously.

In any given semester, a good number of non-majors enroll in my family communication course. Based on feedback from previous end-of-semester student evaluations, non-majors often report perceiving nothing worthwhile was accomplished, that communication majors "overshare," and that they feel 
extreme cognitive and emotional overload (King \& Wheeler, 2019). To be honest, I, too, have often finished class feeling exhausted and wondering if this is a communication course or a therapy session.

This essay illustrates how I attempt to address this problem of engaging both non-majors and majors in meaningful ways that avoids the exhaustion that may come from "oversharing." More specifically, I enrolled in a Scholarship of Teaching and Learning (SofTL) faculty development program. I chose to focus on the family communication course in it because I understand that I am not alone in struggling with helping non-majors see the relevance of the course to them and their life goals (Wang \& Child, 2019). I, like my colleagues, have also noticed the variety of different experiences students bring with them to the family communication course, as well as what some are comfortable and not comfortable sharing. Because I believe it is important to create a climate where all students feel comfortable sharing and applying the course material in the appropriate contexts, I chose to focus on redesigning the family communication course based on Project-Based Learning (PBL).

I have arranged my explanation by first defining SofTL and PBL; then discussing how I transformed a face-to-face section of family communication using it; and, finally, providing advice for faculty who may find themselves in a similar situation.

\section{Scholarship of Teaching and Learning (SofTL)}

In Spring 2018, the Office of Academic Affairs sent out a call inviting faculty to pilot a SofTL Faculty Learning Community. Five faculty members from across the university were accepted into the program and tasked with (a) implementing an active learning strategy into a course, (b) collecting data, and (c) disseminating results either through a conference presentation and/or a journal article. As I mentioned earlier, I chose the family communication course where I would implement a semester-long group project based on PBL.

The purpose of SofTL is to "(1) make the work of teaching and learning public by documenting it; (2) subjecting it to peer review and critique so that (3) it can be built upon” (Hutchings, 2003, p. 57). By participating in SofTL, I heed the call to be more engaging, autonomous, and authentic in the classroom and provide cooperative learning processes (Hutchison, 2016). SofTL provides me an opportunity to test a pedagogical strategy by examining the degree to which it achieves the desired learning outcomes (affective, behavioral, cognitive). Moreover, I can also test my personal teaching philosophy that learning occurs best when students are able to utilize their knowledge outside of the classroom (Schwering, 2015). To explain what I did, the following paragraphs describe the course and the project I integrated as a result of my SofTL experience.

\section{Family Communication}

Family Communication (COM 310) is an elective for communication majors and minors at my university. Moreover, this 300-level upper-division course attracts students from many other disciplines (e.g, computer science, nursing, general studies, human services). The course is also one of several options for students pursuing a Certificate in Gerontology (a popular certificate program for Communication Sciences and Disorders students), as well as for the Death Education Certificate program soon to be offered by the Department of Psychology. 
Wang and Child (2019) advocate that family communication students ought to get out of the classroom to interact with others based on what they learn. I designed the semester-long PBL project based on this philosophy.

\section{The Project-Based Learning Project}

Good PBL projects allow students to take ownership in their knowledge acquisition and use. Through active learning strategies, students do more than passively listen to a lecture and, perhaps, take notes (Stearns, 2017). Moreover, "active learning at its most extreme is student learning with no teacher interference" (Waldeck \& Weimer, 2017, p. 248). As students see their ideas put to work (Boss, 2015), they gain confidence not only as an individual but also as a member of a group (Rice \& Shannon, 2016). Good PBL design employs scaffolding, which is deconstructing the primary goal into smaller sub-goals that build on each other. Finally, because PBL is cyclical, each of these parts should have a clearly identifiable purpose and should count for something toward the overall project grade (Rice \& Shannon, 2016).

To employ PBL, one must start with an open-ended question to essentially drive the project. This question influences the structure as well as the design of each of the sub-goal assignments (Hutchison, 2016). I actually began with two questions:

- What is the importance of stories within the realm of family communication?

- How can these stories be preserved?

As the project design evolved, the question changed to include the variable of preserving stories based on stories from survivors of the Paradise wildfires. Many talked about how "we lost everything," which led me to ponder how we could preserve family stories.

First, I placed students into groups, four or five students per group, and asked them to define family and then to list possible "families" within the local minor league hockey community (e.g., fans, team personnel, players). Because the minor league hockey team was just down the street from the university, it seemed to be a convenient group on which to focus the project. In addition, the hockey team has been a part of the local community for 60 years. Thus, the city residents feel a strong connection to them. The students were asked to choose one "family" from whom they would collect and record stories. Some groups examined season ticket holders, while other groups looked at casual fans, or fans who considered themselves to be life-long fans of the team. No matter what group of fans the students looked at, the students focused strictly on hockey fans as a family.

Second, I divided the semester-long assignment into four scaffolding assignments, each of them due at various points throughout the semester. The scaffolding technique is a useful strategy for large projects in that it encourages students to do the work in segments, solicit feedback, and make revisions. It also discourages procrastinating until the last minute to complete the assignment (Wood et al., 1976).

Third, following PBL guidelines, I was intentionally "hands-off" with all groups. My philosophy, although not necessarily well-received by all, was "I provided what you must accomplish, how you go about it is up to you." 


\section{Addressing the Problem(s)}

Results from a post-project student evaluation showed that non-majors did engage effectively in this assignment. In previous semesters, students would ask questions such as, "How is this [family communication] science?" or "Why do we need to know this?" This time, however, students reported that it was relevant and meaningful. For example, some students noted that the course objectives were reflected in the project. The two major course objectives focused on critical thinking and application. One student wrote, "Helped me to get a better feel that it isn't just useless knowledge and can actually be applied to real people." Another student wrote, "I was able to understand communication between families and friends and how important it is." Others wrote that they are "able to analyze stories" and "come to terms with differences in family communication and concepts that bind it" as an outcome of the assignment. Critical thinking reflects how students absorbed and applied what they learned outside the classroom. These are the "aha" moments captured from the experience. For example, "It [the project] made us look for real life examples." By capturing community stories and analyzing them, students practiced the skills using a critical eye.

Next, students were asked how comfortable they were in applying class material to the project. Two themes emerged: (a) the importance of family and family communication; and, (b) the ability to see and apply theory. Some students were excited that the fans "were more than willing to engage in our project and very eager to share what being a follower of our local team means to them and their families." The connection of "the family dynamics and how they are affected by the community" was made, suggesting that families are influenced by things outside of their unit such as the culture. The culture of the fan community played a part in how a lot of fans defined their involuntary and voluntary families.

Students saw and used theory at work in the project. One student wrote, "I was able to apply certain theories to real families." A classmate said, "the connection between theories and familial communication," and a third wrote, "I can how show different things apply to a theory without usually thinking about that." As one student put it, "theories we learned in class applied to stories in the community."

Finally, working in small groups throughout the semester decreased the perception of "oversharing" expressed by students in previous semesters and less of the class becoming a therapy session. Also, rather than ask students to share their personal experiences, I assigned scholarly readings that employed autoethnographic or narrative methods. As a result, groups were able to discuss and apply "safe material" rather than stress about having to share personal examples and fear judgment from their classmates.

\section{Lessons and Advice}

While I was pleased with what students accomplished, I did learn from this experience. First, despite my good intentions and having a colleague review the assignment before the semester started, the project did become overwhelming for the students. Many had never attended a hockey game, nor did they know anything about the sport. These students were resisters. Also, although the hockey organization provided free admission for these students, fewer than half of the class took advantage of this opportunity. Most said they could not attend a game because they had to work. One best practice I learned from this experience is to allow student groups to select their own community partner at the beginning of the semester rather than assigning one to them. 
Second, I knew some students would be uncomfortable with the lack of specifics provided in the assignment directions. However, just as Melo and Johnson (2016) discovered, the positive feedback outweighed the negative in this regard (about 5\% of the class expressed frustration). One student was adamant about needing more direction as "the project was confusing" and that it "didn't really help."

To address this issue, I have already narrowed the assignment from PBL to CBL (case-based learning). In addition to assigning the research articles, I now ask students to also read a family-based case studies textbook. Doing so provides even more opportunities to discuss difficult topics in a safe realm and critically apply course content to examine the cases. As Wang and Child (2019) suggest, I now ask student groups to write a case study on a family issue. Students work together to define a family problem, look at the problem from various perspectives, and write a case study.

A third lesson I learned was how much students focus on the stories rather than the artifacts that support the stories. Because of the influence of the Paradise Wildfires on the design of the assignment, I had hoped students would see and understand why certain family heirlooms and photos should be preserved. Some of the groups accomplished this by providing photos of different jerseys worn throughout the years, annual family pictures at games, and even preserving the recordings of their participants' stories. In this way, I hoped they would realize that the "stuff" we keep isn't just stuff. This "stuff" opens the door to a memory that can be preserved through the story.

Finally, PBL supported skills for the non-majors represented, as well as enhanced family communication within the students' families. As Melo and Johnson (2016) suggest, non-majors were able to enhance some of the core skills from their major while integrating new skills. The nursing and health \& human services students were instrumental in designing and asking questions to obtain information from their project participants, something they would need to be comfortable with when entering their respective fields. Computer science majors practiced code and design. The ability to enhance their outside skills then provided them opportunity to learn soft skills, such as small-group communication and time management (Freeman et al., 2015). One group learned that a lack of effective soft skills from one team member influenced their final output; consequently, this group practiced the skill of conflict management. No matter the skills learned in family communication, non-majors are equipped to take these skills with them into their other courses.

By doing this project, students took the skills and practiced with their families. An older student in the course demonstrated the importance of family tradition, a unit the project touched upon, by starting a new tradition with her grandsons. They attended three more games after the initial "introduction to the sport" game. Students formed strong interpersonal relationships with their group members as well. One semester removed from the project, I walked across campus and see duos or trios hanging out together. Not only did they study family, but they found voluntary family on campus as well.

\section{Conclusion}

Trying something new is never easy. Although I teach family communication often, I still evaluate and reflect on every assignment, every decision, and every evaluation. Wang and Child (2019) are correct when they argue that students want to be able to apply and get out of the classroom. Our struggle as instructors is finding ways for students to accomplish both. No doubt, we will continue to struggle with reaching non-majors that take our communication course. This pedagogical experiment serves as one small step toward closing that gap. 


\section{References}

Boss, S. (2015). Implementing project-based learning. Solution Tree Press.

Freeman, C., Miller, P. B., Kobia, C., \& Lee J. (2015). What do students really learn from a fashion show? A theoretical approach to project-based learning activity. International Textile and Apparel Association (ITAA) Annual Conference Proceedings, 84. http://lib.dr.iastate.edu/itaa_proceedings/2015/ posters/84

Hutchings, P. (2003). The scholarship of teaching and learning in communication: A few words from the Carnegie academy. Communication Education, 52(1), 57-59. https://doi.org/10.1080/03634520302455

Hutchison, M. (2016). The empathy project: Using a project-based learning assignment to increase firstyear college students' comfort with interdisciplinarity. Interdisciplinary Journal of Problem-Based Learning, 10(1). https://doi.org/10.7771/1541-5015.1580

Keshwani, J., \& Adams, K. (2017). Cross-disciplinary service-learning to enhance engineering identity and improve communication skills. Internal Journal for Service Learning in Engineering, Humanitarian Engineering, and Social Entrepreneurship, 12(1), 41-61.

King, M. E. \& Wheeler, A. (2019). Reducing secondary trauma and compassion fatigue in the dark side of interpersonal communication classrooms. Journal of Communication Pedagogy, 2, 90-95. https:// doi.org/10.31446/JCP.2019.17

Melo, M., \& Johnson, A. (2016). Teaching technical writing through designing and running escape rooms. Dialogue: The Interdisciplinary Journal of Popular Culture and Pedagogy, 5(2), 1-13. http:// journaldialogue.org/wp-content/uploads/2018/06/2-Melo-Johnson.pdf

Rice, M., \& Shannon, L. (2016). Developing project learning, integrated course from two colleges at an institution of higher education; An overview of processes, challenges, and lessons learned. Information Systems Education Journal, 14(2), 55-62. https://files.eric.ed.gov/fulltext/EJ1136184.pdf

Schwering, R. E. (2015). Optimizing learning in project-based capstone courses. Academy of Educational Leadership Journal, 19(1), 90-104.

Stearns, S. (2017). What is the place of lecture in student learning today? Communication Education, 66(2), 243-245. https://doi.org/10.1080/03634523.2016.1275723

Waldeck, J. H., \& Weimer, M. (2017). Sound decision making about the lecture's role in the college classroom. Communication Education, 66(2), 247-250. https://doi.org/10.1080/03634523.2016.1275721

Wang, T. R., \& Child, J. T. (2019). Perspectives on teaching the family communication course. Journal of Pedagogy, 2, 3-6. https://doi.org/10.31446/JCP.2019.02

Wood, D., Bruner, J. S., \& Ross, G. (1976). The role of tutoring in problem solving. Journal of Child Psychology and Psychiatry, 17(2), 89-100. https://doi.org/10.1111/j.1469-7610.1976.tb00381.x 